\title{
Exploring the use of blogs as learning spaces in the higher education sector
}

Jeremy B Williams

Universitas 21 Global

\section{Joanne Jacobs}

Queensland University of Technology

'Blogging' - a contraction of the term 'web logging' - is perhaps best described as a form of micro-publishing. Easy to use, from any Internet connection point, blogging has become firmly established as a web based communications tool. The blogging phenomenon has evolved from its early origin as a medium for the publication of simple, online personal diaries, to the latest disruptive technology, the 'killer app' that has the capacity to engage people in collaborative activity, knowledge sharing, reflection and debate (Hiler, 2003). Many blogs have large and dedicated readerships, and blog clusters have formed linking fellow bloggers in accordance with their common interests.

This paper explores the potential of blogs as learning spaces for students in the higher education sector. It refers to the nascent literature on the subject, explores methods for using blogs for educational purposes in university courses (eg. Harvard Law School) and records the experience of the Brisbane Graduate School of Business at Queensland University Cof Technology, with its 'MBA blog'. The paper concludes that blogging has the potential to be a transformational technology for teaching and learning.

\section{Introduction}

'Blogs' have evolved along similar lines to other forms of human communication in that they are a product of convenience rather than design. Based on the reverse chronological posting of news items, invariably containing hyperlinks to third party sites, and an opportunity for readers to enter personal responses to articles, this otherwise quite organic and unstructured format of delivering information via the World Wide Web (WWW) came to be known as 'blogging', after 'web log' was abbreviated to 'blog' (Jacobs, 2003, p. 1). 
The origins of the blog is the subject of some debate, but according to Blood (2000), the phrase 'web log' was first used by Barger (1997) and the shortened version by Merholz in 1999 (Merholz, 2002). Blogging as a phenomenon started to increase steadily after this time, and then there was an explosion in the number of blogs when the first free, do it yourself blogging tools became available in mid-1999, most notably Blogger.com. The purists within the blogging community ('the blogosphere') would likely claim, though, that blogging really started in 1992 with the first web site (Berners-Lee, 1992), followed by Netscape's 'What's New!' page for users of its new web browser in 1993. However, neither really come close to the current notion of a blog, and in this sense Scripting News (the brainchild of blogger 'guru' Dave Winer), and Slashdot (both of which started in 1997) stand out as important precursors.

Others might point to the fact that online collaborative workspace in the form of 'wiki' predated any developments in the blogosphere. Wiki, a piece of server software that permits users to freely create and edit web content via any browser, supports hyperlinks and has a simple text syntax for creating new pages. The first ever wiki site was created for the Portland Pattern Repository in 1995, a site that now hosts tens of thousands of pages. Since this time, wiki has enjoyed varying degrees of success, partly due to variability in users' collective enthusiasm for creating content. Blogs, on the other hand, boast a level of participation not previously experienced by the earlier wiki initiative, and a greater sense of community and debate is encouraged as a consequence.

Now firmly established as a web based communications tool, with an estimated number of users in excess of one million (Bryant, 2003), blogs have emerged from early email lists and instant messaging communities as a means of informing a dedicated reader base about items of interest to the authors, news, and personal information. But the blog is a whole lot more besides. It is also a means of reaching a wider audience; an unknown mass of 'netizens', ready and willing to respond to the opinions and commentaries of bloggers in a manner not dissimilar to that afforded a talkback radio host. With a 'soapbox' all to themselves, blogs provide their maintainers with the rare opportunity (for the vast majority, at least) to act as an oracle of information. More importantly, perhaps, the publication of one's personal thoughts for the public consumption of such a vast audience can be an uplifting and sometimes cathartic experience (Jacobs, 2003, p. 2).

The key to the popularity of blogs, it seems, is the scope for interactivity. While, initially, a blog may be treated by its maintainer as little more than a 'news space', it is not uncommon, over a period of time, for a distinctive style to emerge, in the course of writing entries and responding to 
feedback, that reflects the personal character of the blog's creator. Significantly, rather than alienate a readership by exposing one's personal traits and idiosyncrasies, this adds to the very popularity of a blog. As Jacobs explains, this is part and parcel of the theatre of interpersonal communication, played out to an undefined, virtually infinite public space. Indeed, this 'exhibitionistic behaviour is encouraged, supported and even sought' by the 'cyber-voyeurs' of this theatre; viz. 'the readers of blogs, who post comments in reply to entries, often positively reinforcing the opinions of the blogger, but sometimes disagreeing on points of philosophy, politics or social comment, and occasionally 'flaming' the blogger for opinions expressed' (Jacobs, 2003, p. 2).

Blog pundit John Hiler has described the blog as 'the latest disruptive technology', the 'killer app' that has the capacity to engage people in collaborative activity, knowledge sharing, reflection and debate, where complex and expensive technology has failed (Hiler, 2003). Indeed, the great beauty of blogs is their versatility. They cater for a wide diversity of interests and uses and there is no rule that states a blog has to be owned and operated by an individual. There are group blogs, family blogs, community blogs, and corporate blogs, and then there are blogs defined by their content; eg. 'WarBlogs' (a product of the Iraq War), 'LibLogs' (library bogs), and 'EduBlogs', a new type of blog that has begun to emerge in educational circles.

The simplicity of the mechanism of blogging as a public space for comment and information dissemination has also attracted the interest of the business community, culminating in the first international conference on the business use of blogs in the United States in June 2003, and in the development of commercially hosted blogging spaces such as the Socialtext initiative. Bausch, Haughey \& Hourihan (2002) argue that while formal knowledge management tools are complicated to implement and may be deemed an imposition on the time of a worker, informal systems such as blogs provide an opportunity to capture knowledge where it is created in an organisation, sharing that knowledge throughout an organisation.

Furthermore, the nature of blogging engines allows for the creation of a legitimate warehousing of captured knowledge, and archiving for later retrieval (Bausch, Haughey \& Hourihan, 2002). As a knowledge management tool, blogs provide the potential for relatively undifferentiated articles of information passing through an organisation to be contextualised in a manner that adds value, thus generating 'knowledge' from mere 'information'. Comments systems and democratic posting privileges allow employees in an organisation to give voice to ideas and provide feedback on procedures in a manner not previously 
possible in a distributed office environment. Further, personalised responses to news and messages are a simple means of developing an understanding of the collective knowledge of an organisation and a means of broadening that knowledge, thus creating 'intelligence' from 'knowledge' (see Pór \& Molloy 2000). Thus, in a business context, blogs provide a forum for learning. It logically follows therefore, that the experience of collective knowledge generation can and should be applied to traditional educational environments.

The chief purpose of this paper is to comment, critically, on the potential for blogs as 'learning spaces' for students within the higher education sector. To this end, there will be reference to the nascent literature on the subject, how personal blogs have been harnessed for educational purposes in university courses (e.g. Harvard Law School), and how the Brisbane Graduate School of Business (BGSB) at Queensland University of Technology (QUT) fared when experimenting with a group 'MBA blog'. The paper concludes that blogging has the potential to be a transformational technology for teaching and learning, and universities ought to give strong consideration to the setting up blog facilities within their learning management system (LMS).

\section{Academic literature on blogging}

Surprisingly, there is not a lot of refereed published material on the subject of blogs in general, let alone work that focuses specifically on blogs in education. Combined searches on ProQuest, EBSCO and Gale yielded only 30 results in peer reviewed scholarly journals, and the bulk of these are focusing on the influence of blogging on journalism and reporting. Given that blogging can be reasonably described as a form of micro-publishing, it is no great shock that blogging is a phenomenon that grabs the attention of this particular academic community (see, for example, Welch, Jensen \& Reeves, 2003). It should also come as no surprise that many journalists view blogging with a touch of cynicism, understandably sceptical, perhaps, that a bunch of amateurs could possibly be a serious threat to their profession (see, for example, the pessimistic view espoused by Thompson 2003). The fact remains, however, that blogging is no passing Internet fad, available data showing that, while bloggers come and go, the blogosphere continues to expand unabated (Whelan 2003). The latest forecasts suggest that the number of hosted blogs created will exceed five million by the end of 2003, and ten million by the end of 2004 (Henning 2003).

Another observation one might make of the existing academic literature on blogging is that in those instances where educational applications of the blog are considered, this literature tends to be concentrated in the areas of 
teacher training and other professions where the use of reflective journals as a learning tool is accepted custom and practice, and where, as a consequence, there is an increased likelihood of a favourable disposition to blogs in the first place (eg. Stiler \& Philleo, 2003; Wagner, 2003). Another area that has responded positively to blogging is librarianship, where information search and retrieval skills are integral to the job. Here, again, one might expect a natural predisposition to the idea of the blog (see, for example, Embrey, 2002; Clyde, 2002).

One article that reflects a little more deeply on the potential of the blog as a tool for the promotion of deeper learning on a variety fronts is that produced by Oravec (2002). In addition to commenting on the advantages of using a tool that serves as an online journal encouraging personal reflection, and as a means of encouraging collaboration through the sharing of links to resources and up to date information, Oravec (2002, p. 618) observes that the blog has many dimensions that are suited to students' 'unique voices', empowering them, and encouraging them to become more critically analytical in their thinking. The reason, simply, is that in order to develop and sustain a clear and confident voice of one's own, one has to carefully formulate and stand by one's opinions. Writing a blog assists here because it forces a student to confront their own opinions and contemplate how their views might be interpreted and reflected upon by others (Mortensen \& Walker, 2002, cited in Lamshed, Berry \& Armstrong, 2002).

The research of Ferdig \& Trammel (2004), drawing on educational theories of Vygotski (1978), is also significant in assessing the educational value of blogs. They argue that the discursive nature of knowledge construction is best addressed by the immediacy and commentary based system of blogging. They observe that there will be a natural tendency for reflection and analysis on the part of the student, given feedback systems are integral to the blogging interface, but also note that the contextualisation of learning through hypertext links to other materials encourages revisiting and revising of learned concepts, enriching the learning experience. Compared to asynchronous discussion forums such as newsgroups and bulletin boards, Ferdig \& Trammel (2004) contend that blogs are more successful in promoting interactivity that is conversational; a mode of interaction more conducive to improved student and teacher relationships, active learning, higher order thinking, and greater flexibility in teaching and learning more generally.

The dearth of scholarly journal articles on the blogging phenomenon notwithstanding, 'non-refereed' commentary is quite voluminous. The phrase 'non-refereed' appears in a set of inverts here quite deliberately, because much of this commentary (as one might expect!) is located on 
various EduBlog sites around the world (see, for example, Weblogg-ed and Weblogs in Higher Education, both of which incorporate high quality work along with an abundance of 'referees' only too willing to offer their constructive criticism. In summary, therefore, although one might be led to the conclusion that academics have been a little slow getting out of the starting blocks, the fact of the matter is that blogging, for all intents and purposes, is a grassroots phenomenon. For this reason, academic bloggers, if they are true to their ideals, may be more concerned about spreading their message in the blogosphere than in the 'Journal of Obscure Facts'! Meanwhile, for the non-blogging academic community, it may be a case of insufficient time having passed yet for blogging to penetrate the outer shell of their paradigm. For them, blogging seems to be working in practice, but does it work in theory? ${ }^{1}$

\section{Weblogs at Harvard Law}

A number of universities round the world have commenced with the use of blogging tools including, for example, the University of Iowa, Rice University and Harvard University. Plans to use blogs have also been implemented at Stanford University and RMIT University in Melbourne. The 'Weblogs at Harvard Law' hosted by the Berkman Center for Internet \& Society at Harvard Law School is, perhaps, the most impressive of these initiatives, due in no small part, one would imagine, to the influence of Dave Winer, a Berkman Fellow and long time blog guru.

The first blogging initiative at a major educational institution, the initiative arose following a conference at the Berkman Center in November 2002 entitled: 'What Is Harvard's Digital Identity?' At this conference, Provost Steven Hyman challenged the assembled deans, faculty members and administrators to harness the power of the Internet to break down the silo mentality and build intellectual bridges that would facilitate the flow of information and ideas between the University's disparate schools and centres.

While still in its infancy (commencing in early 2003), the Harvard Weblogs project has already made great strides. The Berkman Center hosts the blogs on a dedicated server, provides software and support, and aggregates and ranks blogging activity. Anyone with a harvard.edu email address can create a new weblog free of charge. Numerous personal blogs

${ }^{1}$ The appendix to this paper provides an annotated bibliography of source materials on the use of blogging in learning environments, and contains some links to examples of blog use in higher education contexts. This is designed as a guide for instructors on potential applications of blogging, and offers some insights into the educational theory supporting the use of blogs in any LMS. 
feed off the Weblogs at Harvard Law 'group' blog co-edited by Winer and, indeed, off each other, promoting lifelong learning and helping to bind a community around the common theme of Harvard University and scholarly discourse.

\section{The BGSB MBA blog}

In 1999, the BGSB introduced an innovative new MBA course offering prospective students greater flexibility and choice, and improved services such as study guides and online learning and teaching (OLT) sites for each course unit. This initiative has proved to be a major success, student numbers trebling at the same time as course fees have more than doubled and entry standards have been lifted.

Funded entirely from student fees, the BGSB, like other institutions in the same position, is very sensitive to market perceptions of its services. One strategy actively pursued by the School has been to gain an international reputation for the flexible delivery of its programs. Flexible delivery is, by definition, a client oriented approach because it is a commitment, on the part of the education provider, to tailor courses to meet the various individual needs of its students. Furthermore, it is tacit recognition of the fact that the student profile has changed quite dramatically - socially, culturally, economically - and that, pedagogically, there is a need for a student centred curriculum to cater for this increasingly diverse student body.

Integral to this strategy has been the development of OLT sites. The framework for OLT sites varies from course unit to course unit but, typically, there is a download facility where students can access PowerPoint lecture slides, WWW links, solutions to problems, past examination papers, chat space, and discussion forums (electronic bulletin boards). An important impetus for the introduction of a blog tool within this environment was a general feeling of dissatisfaction with participation levels in discussion forums.

It was decided that an 'MBA blog' would be trialled with students from two course units being encouraged to participate by making contributions based on the subject matter they were studying; viz. macroeconomics and international political economy. While no specific instructions were given to students one way or another, the administrators of the blog fully expected there to be some cross-course unit discussion, and this is precisely what happened. Indeed, very little advice was given to students as to how they should proceed, other than how to log on, and how to use the blog editing facilities. In short, it was decided that the blog ought to be as student centred as possible, with the students themselves determining 
what shape and form the blog should take. Participation in the blog was optional, but students were advised that five 'meaningful' contributions in the six-week period of the unit would be sufficient to earn them five marks (within the flexible assessment system used in both course units). Ultimately, around one half of enrolled students elected to participate.

Tables 1 to 5 present the results of an online questionnaire open (over a 4week period during June and July of 2003) to all students who had been enrolled in the two course units (GSN414 and GSN451) involved in the trial. There were 51 respondents, a response rate of exactly 50\% (there being 102 students enrolled in the two classes). Note that the 'no answer' response was removed from percentage calculations and these percentages may not add up to $100 \%$ because of rounding.

Table 1: Reasons for not participating in the blog

\begin{tabular}{|l|c|c|}
\hline $\begin{array}{l}\text { Question 1: If you elected not to participate in the MBA Blog, which of } \\
\text { the following options best describes the reason for your decision: }\end{array}$ & Score & $\%$ \\
\hline A. For the marks available, it wasn't worth the effort. & 8 & 33 \\
\hline $\begin{array}{l}\text { B. I would have liked to participate, but I wasn't sure I'd have anything } \\
\text { valuable to contribute. }\end{array}$ & 8 & 33 \\
\hline $\begin{array}{l}\text { C. I would have liked to participate, but I had difficulty coming to } \\
\text { terms with the technology. }\end{array}$ & 1 & 4 \\
\hline D. I just preferred to read what other people were writing. & 2 & 8 \\
\hline E. Other reason. & 5 & 21 \\
\hline F. No answer. & 27 & \\
\hline
\end{tabular}

F. No answer.

Just under half of the respondents declared that they did not participate in the blog, yet several individuals went on to complete the questionnaire even though they were not required to having given an answer in Question 1. As students were provided with the option of adding comments to elaborate on their responses to each question, it transpired that this may be explained in terms of students' interpretation of the word 'participate'. 'Lurking' on the blog is participation in some people's minds. As one student put it:

'Reading what other people were writing was valuable. It was therefore not so much a choice of not participating, it was more a choice not to contribute.

I viewed myself as having participated, and will therefore answer the rest of the questions.'

To support this, Allen (2002) has argued that by observing the behaviours of participants in a computer mediated community, 'lurkers' can become familiar with the ways of participating and overcome fears. Indeed, Nonnecke \& Preece (2001) maintain that lurking is an imperative aspect of an online community and should be regarded as a form of passive or vicarious participation that not only serves to increase the understanding 
in the lurker, but provides a sense of belonging regardless of whether they ever intend to participate. There is also the possibility that active participants in an online community 'perform' to a potential readership that may or may not eventually become active participants in a community. Thus, active participants may well assume a lurking audience as part of the accepted risk of rebuttal, in creating an argument or expressing a theory in making a blog entry. This risk, in turn, develops skills among active participants in critical thinking and argument creation.

Table 2: The blog as a medium for facilitating learning

\begin{tabular}{|l|c|c|}
\hline $\begin{array}{l}\text { Question 2: If you did not participate in the MBA Blog you do not } \\
\text { need to answer any further questions. Thank you for your input. If you } \\
\text { did participate, please answer this question and questions 3-5. Do you } \\
\text { think the MBA Blog assisted with your learning in GSN414/GSN451? }\end{array}$ & Score & $\%$ \\
\hline A. Strongly agree & 6 & 17 \\
\hline B. Agree & 17 & 49 \\
\hline C. Neither agree nor disagree & 8 & 23 \\
\hline D. Disagree & 2 & 6 \\
\hline E. Strongly disagree & 2 & 6 \\
\hline F. No answer. & 16 & \\
\hline
\end{tabular}

The quantitative data in response to Question 2 would appear to lend reasonably strong support for the continued use of blogs, some two thirds of blog participants either agreeing or strongly agreeing that the MBA blog assisted their learning (only 12\% disagreeing or strongly disagreeing). The following comments provide further endorsement:

'Even though at first people were afraid to take the risk and blog, I found it a good way to discuss concepts and participate in further discussion. It also allowed the sharing of up-to-date information that would not have been possible in lecture time."

'I spent time prior to each blog constructing an entry. To do that I did need to have a good understanding of what I wanted to blog about. I also spent time reading and considering the blogs of other students and found their comments and perspectives thought provoking.

I particularly enjoyed seeing the almost daily observations of students of the applications of the 414 theory and [the] "thinking about things" technique.'

'I felt that it offered a method to give comment on a wide range of macroeconomic issues that started debate and interesting conversation.'

There was stronger endorsement for the view that the MBA Blog increased student interactivity, some $77 \%$ of students either agreeing or strongly agreeing that the MBA blog increased the level of meaningful intellectual 
exchange between students (only 3\% or one person disagreeing with this statement). The written comments in response to Question 3 were equally emphatic:

'It provided a medium for intellectual exchanges, and with further use I think that the quality of these exchanges would only get better.'

' 6 week module timeframes can create significant challenges for opportunities for discussion and debate amongst participants - blogging offers an opportunity to express one's thoughts \& to be party to the thoughts of others - often quite stimulating. The MBA in my view is about more than the "data" - it is the process of thinking which develops intelligence.'

'Yes, once I got the hang of it I could see it encouraged me to contribute and interact with other students in a way I wouldn't normally find time to do at Uni.'

'Students could put forth their ideas on topics after a little thought. The only other avenue available most of the time is in-class comments, for which you do not have much time to really think about them in detail.

When new to a subject, the extra thought time that blogging provides can really help students sort through some of the issues in our own head, before providing them for all to see.

\section{Table 3: The blog as a medium for student interactivity}

\begin{tabular}{|l|c|c|}
\hline $\begin{array}{l}\text { Question 3: Do you believe the MBA Blog increased the level of } \\
\text { meaningful intellectual exchange between students more broadly? }\end{array}$ & Score & $\%$ \\
\hline A. Strongly agree & 6 & 17 \\
\hline B. Agree & 21 & 60 \\
\hline C. Neither agree nor disagree & 7 & 20 \\
\hline D. Disagree & 1 & 3 \\
\hline E. Strongly disagree & 0 & 0 \\
\hline F. No answer. & 16 & \\
\hline
\end{tabular}

Table 4: The blog as a medium for reflection

\begin{tabular}{|l|c|c|}
\hline $\begin{array}{l}\text { Question 4: Having experienced the MBA blog, and knowing what } \\
\text { you know now, would you participate in something similar in the } \\
\text { future if the activity were purely for formative purposes (i.e. it did not } \\
\text { count at all towards the formal assessment for the unit)? }\end{array}$ & Score & $\%$ \\
\hline A. Strongly agree & 8 & 22 \\
\hline B. Agree & 17 & 47 \\
\hline C. Neither agree nor disagree & 4 & 11 \\
\hline D. Disagree & 6 & 17 \\
\hline E. Strongly disagree & 1 & 3 \\
\hline F. No answer & 15 & \\
\hline
\end{tabular}


The responses to Question 4, meanwhile, revealed perhaps the most satisfying finding from the point of view of an educator; viz. that more than two thirds of blog participants would still have taken part had there not been the incentive of marks counting towards their final score. Some students were quite dismissive of the idea of having the exercise count towards summative assessment:

'I participated when I felt that I had something to say, not because I was receiving marks for it.'

'Learning is for ourselves not just for marks.'

'Yes, I found it very interesting what other student found relevant of the course and the newspapers (a bit like a Readers Digest).'

'Yes, I felt the pressure to construct some high level comment detracted from the spontaneity of the blog. Other students commented to me that it was not as conversational as they expected - for the reason that it was part of the formal assessment.'

While it would overly optimistic to assume that this is the case in every degree course, it is a reasonable assumption to make in a full fee paying MBA course, where the bulk of students are mature age students, primarily motivated to learn skills rather collect letters after their name. Importantly, as Wrede (2003) observes, 'if professors want students to become autonomous, creative, helpful and cooperative, educational institutions must actually allow students to practice exactly these skills ... by designing curriculums and courses that really value these qualities.' The inherent creativity of blogging and the distinctly open environment for topic advancement allowed students to direct their own learning in a manner that transcended the existing curriculum.

Table 5: The transferability of blogging as a learning tool

\begin{tabular}{|l|c|c|}
\hline $\begin{array}{l}\text { Question 5: Would you like to see blogging used more widely in the } \\
\text { MBA as a learning/assessment tool? }\end{array}$ & Score & $\%$ \\
\hline A. It should be used in all MBA units & 9 & 26 \\
\hline B. It should be used in most MBA units & 11 & 31 \\
\hline C. It should be used in some MBA units & 13 & 37 \\
\hline D. It should be used in no MBA units other than GSN414 and GSN451 & 1 & 3 \\
\hline E. It should be not be used at all beyond this trial & 1 & 3 \\
\hline F. No answer & 16 & \\
\hline
\end{tabular}

On the question of the transferability of the blog as a learning tool (Question 5), student opinion was more divided, only 57\% confirming that they thought a blog could be used in all or most of the course units in the MBA program, 37\% conceding that it could be used in some units. A common theme in the written comments associated with this question 
(and others) was that a little more structure and coaching on how to blog would have been useful:

'I think more linkages could be made in class time between blog-postings and course content. Rather than sitting on the side, I think the blog could form a central element of the teaching that ties together the lecture material and individual students' own explorations. I think it was an excellent experiment that should be continued.

'I would have felt more comfortable contributing to the blog, if perhaps in the first week, it had been compulsory to make an entry. I found it took a lot of courage for me to make an entry, and as such, did not start participating until week 4 . However, once I participated I found it very beneficial.

\section{Summary and conclusions}

The analysis of both the quantitative and qualitative data collected in the BGSB study shows students to be broadly in favour of the continued use of blogs as an effective aid to teaching and learning. It is clear, though, that results would likely have been more positive had there been greater direction at the beginning of the project as to how one went about blogging, and what students could expect to get out of it. With the benefit of hindsight, it was probably a mistake to include contributions to the MBA blog as an optional assessment item. Some students clearly submitted solely for the sake of getting the marks (invariably the weaker students) and this detracted from the overall quality of the experience for some students.

It would appear from a review of the literature on the subject and of current practice at universities that blogs and academic discourse are natural allies. As Allen (1999) puts it:

(T)he really important step forward that universities can take is to begin fostering communities that are less specifically connected to units and are, instead, about issues, subjects, disciplines or professions and which are distinct from those already forming in the virtual world of the Internet by being associated with overall courses offered by that university. Student membership of these communities should become integral to their course completion; where necessary, whole components of the course should become (instead of 'study') knowledge-based community participation (Allen 1999).

Blogs are perhaps the most obvious realisation of Allen's vision to provide a forum for academic discourse that reaches beyond the scope of a university subject and which augments the knowledge creation occurring throughout a student's enrolment in a higher education program. 
Students have long learned as much from each other as they have from an instructor or a textbook - it's just a question of finding an appropriate vehicle for facilitating this learning. The 'cut and thrust' of the MBA classroom has performed such a function for many years and will likely continue to do so for some time to come, but the blog provides another such forum, one that successive generations of students will feel increasingly comfortable with, as it becomes more commonplace for people to engage with one another online rather than on campus. (Indeed, some might argue that we have already gone past this point.) In short, blogs have the potential, at least, to be a truly transformational technology in that they provide students with a high level of autonomy while simultaneously providing opportunity for greater interaction with peers. A blogging tool would be a valuable addition, therefore, to any LMS.

\section{References}

Allen, M. (2002). Voluntary participation in CMC tends to be limited. [Verified 6 June 2004] http:/ / www.curtin.edu.au/home/allen/we3/igm/12050101.htm

Allen, M (1999). Don't be a troll! Using the Internet for successful higher education. [Verified 6 June 2004]

http:/ / smi.curtin.edu.au/NetStudies/docs/allen/ AllenHighered1999.doc

Baker, H.J. (2003). The learning log. Journal of Information Systems Education. 14(1) $11-14$.

Barger, J. (1997). Robot wisdom weblog for December 1997. [Verified 6 June 2004] http: / / www.robotwisdom.com/ $\log 1997 \mathrm{~m} 12 . \mathrm{html}$

Bausch, P., Haughey, M. \& Hourihan, M. (2002) We Blog: Publishing Online with Weblogs, New York: John Wiley \& Sons, (Chapter 8). [Verified 6 June 2004] http:/ / www.blogroots.com/ chapters.blog/id/4

Berners-Lee, T. (1992). What's new in '92. [Verified 6 June 2004] http:// www.w3.org/History/19921103-hypertext/hypertext/WWW/News/9201.html

Blood, R. (2000). Weblogs: A history and perspective. [Verified 6 June 2004] http:/ / www.rebeccablood.net/essays/weblog_history.html

Bryant, L. (2003). Smarter, simpler, social: An introduction to online social software methodology. [Verified 6 June 2004]

http:/ / www.headshift.com/moments / archive/sss2.html

Clyde, A. (2002). Shall we blog? Teacher Librarian, 30(1), 44-46.

Embrey, T. (2002). You blog, we blog: A guide to how teacher librarians can use weblogs to build communication and research skills. Teacher Librarian. December, 30(2), 7-9. 
Ferdig, R. E. \& Trammell, K. D. (2004). Content delivery in the 'Blogosphere'. Technological Horizons in Education Journal, February. [Verified 27 May 2004] http: / / www.thejournal.com/ magazine/ vault/ articleprintversion.cfm?aid=4677

Henning, J. (2003). The blogging iceberg: Of 4.12 million hosted weblogs, most little seen, quickly abandoned. Perseus Development Corporation, October. [Verified 6 June 2004]

http: / / www.perseus.com/blogsurvey/thebloggingiceberg.html

Hiler, J. (2002). Blogs as disruptive tech: How weblogs are flying under the radar of the content management giants. [Verified 6 June 2004] http:/ / www.webcrimson.com/ourstories/blogsdisruptivetech.htm

Jacobs, J. (2003). Communication over exposure: The rise of blogs as a product of cybervoyeurism. In Hatcher, C., J. Jacobs \& T. Flew (Eds), Australian and New Zealand Communication Association Conference Proceedings, Brisbane. [Verified 6 June 2004]

http: / / www.bgsb.qut.edu.au/conferences / ANZCA03/Proceedings/papers/jj acobs_full.pdf

Lamshed, R., Berry, M. \& Armstrong, L. (2002). Blogs: Personal e-learning spaces. [Viewed 12 January 2004] http:// www.binaryblue.com.au/docs/blogs.pdf

Merholz, P. (2002). ‘Play with words'. [Verified 6 June 2004] http:/ / www.peterme.com/archives / 00000205.html

Pór, G. \& Molloy, J. (2002). Nurturing Systemic Wisdom Through Knowledge Ecology. [Verified 6 June 2004] http:/ / www.co-i-l.com/ coil/ knowledgegarden/kd/KE.pdf

Nonnecke, B. \& Preece, J. (2001). Why lurkers lurk. AMCIS Conference, Boston, June. [Verified 6 June 2004]

http:/ / snowhite.cis.uoguelph.ca/ nonnecke/ research/ whylurk.pdf

Oravec, J. (2002). Bookmarking the world: Weblog applications in education. Journal of Adolescent and Adult Literacy. 45(7), 616-621.

Stiler, G. M. \& Philleo, T. (2003). Blogging and blogspots: An alternative format for encouraging reflective practice among pre-service teachers. Education, 123(4), 789-797.

Thompson, W. (2003). All over for blogs?. BBC News, 8 August. [Verified 6 June 2004] http:/ / newsvote.bbc.co.uk/mpapps / pagetools/print/news.bbc.co.uk/2/hi/te chnology/3134629.stm

Vygotsky, L. (1978). Mind in Society. Cambridge, MA: Harvard University Press.

Wagner, C. (2003). Put another (b)log on the wire: Publishing learning logs as weblogs. Journal of Information Systems Education, 14(2), 131-132.

Welch, M., Jensen, M. \& Reeves, J. (2003). Blogworld and its gravity. Columbia Journalism Review. September/October, 42(3), 20-26. 
Whelan, D. (2003). In a fog about blogs. American Demographics, 25(6, July/August) 22-23.

Wrede, O. (2003). Weblogs and discourse: Weblogs as a transformational technology for higher education and academic research. Blogtalk Conference, Vienna, 23- 24 May. [Verified 6 June 2004]

http: / / owrede.khm.de/publications/weblogs_and_discourse_backup

\section{Appendix 1: Resources on blog methods and blogs in} learning

Allen, M (1999). Don't be a troll! Using the Internet for successful higher education. [Verified 6 June 2004]

http:/ / smi.curtin.edu.au/NetStudies / docs/ allen/ AllenHighered1999.doc

This article focuses on the application of the internet to higher education learning, and argues that cooperative systems and online communities present universities with the best opportunity for universities in the commodification of knowledge.

Ferdig, R. E. \& Trammell, K. D. (2004). Content Delivery in the 'Blogosphere'. Technological Horizons in Education Journal, February. [Verified 6 June 2004] http:/ / www.thejournal.com/magazine/ vault/articleprintversion.cfm?aid=4677

This article is the first of the new wave of research focusing on the scholarly arguments for conversational learning, and argues that the intellectual ownership of ideas promoted by the blog structure, as well as feedback and challenging systems integral to blogging environments, allows for a more sophisticated form of active learning and encourages higher-order thinking. The article also offers examples of blog implementation in learning environments.

Wagner, C. (2003). Put another (b)log on the wire: Publishing learning logs as weblogs. Journal of Information Systems Education, 14(2), 131-132.

This article draws on the research of Baker (2003) on learning logs, and Barger (1997) on weblogs, and argues that the benefits of blogs include ease of publication, sharing of results, and instructor monitoring.

Weblogs in Higher Education. [Verified 6 June 2004] http:/ / www.mchron.net/site/ edublog.php

This blog is a collective resource for academics sharing knowledge about use of weblogs and wikis in higher educational contexts.

Teaching Online in Higher Education. [Verified 6 June 2004] http:/ / blogs.panam.edu/wbl/

This blog is focuses on current topics in web based learning and promotes various relevant articles. 
E_Learning Centre's Guide to e-learning. [Verified 6 June 2004] http:/ / www.elearningcentre.co.uk/guide2elearning/2-10/2-10-3.htm

This archive records a series of examples of blog use in higher education contexts, and has a link to a matrix of uses of blogs in education.

Roberts, S. (2003). Campus communications and the wisdom of blogging. Syllabus Magazine: Technology in Higher Education, January. [Verified 6 June 2004] http:/ / www.syllabus.com/article.asp?id=7982

This article considers the range of contexts in which blogs may be utilised to improve the learning experience of students in the higher education sector. It also offers links to opinion based pieces on the matter, and to blog development tools for implementation of a web log.

Carraher, D. (2003). Weblogs in education. [Verified 6 June 2004] http:/ / blogs.law.harvard.edu/carraher/stories / storyReader\$6

This short blog post from a Harvard University pedagogue reflects of the potential value to be added by use of blogs in higher education institutions.

Schroeder, D. (2004). Blogs in Higher Education: Pedagogy, Practice and Really Simple Syndication (RSS). [Verified 6 June 2004]

http: / / www.educause.edu/ir/library/ powerpoint/MWR0408.pps

This PowerPoint presentation investigates the value of RSS syndication techniques for aggregation of data, and provides many links to relevant resources on blogging in educational contexts.

Education blogs from the Blog Search Engine. [Verified 6 June 2004] http:/ / www.blogsearchengine.com/education_blogs.html

This index of education blogs is the result of a search in one of the major search engines focusing exclusively on blogs.

Dr Jeremy B. Williams, Director of Instruction and Assessment, Associate Professor in E-Learning,Universitas 21 Global, 5 Shenton Way, \#01-

01UIC Building, Singapore 068808

Web: http:/ / www.u21global.com/

Personal web: http://www.jeremybwilliams.net/

Email: jeremy@u21global.com

Joanne Jacobs

Brisbane Graduate School of Business, Queensland University of

Technology, GPO Box 2434, Brisbane QLD 4001, Australia

Email: j2.jacobs@qut.edu.au

Web: http:/ / www.joannejacobs.net/ 